\title{
Never forget to consider atrial fibrillation ablation during mitral valve surgery
}

\author{
Leonid Sternik, MD
}

\author{
From the Department of Cardiac Surgery, Sheba Medical Center, Ramat Gan, Israel. \\ Disclosures: Author has nothing to disclose with regard to commercial support. \\ Received for publication July 29, 2018; accepted for publication July 30, 2018; available ahead of print Aug 31, \\ 2018. \\ Address for reprints: Leonid Sternik, MD, Department of Cardiac Surgery, Sheba Medical Center, Ramat Gan, \\ Israel (E-mail: leosternik@hotmail.com). \\ J Thorac Cardiovasc Surg 2019;157:1021-2 \\ $0022-5223 / \$ 36.00$ \\ Copyright (C) 2018 by The American Association for Thoracic Surgery \\ https://doi.org/10.1016/j.jtcvs.2018.07.086
}

It is so nice to read an article reporting on 11,381 patients from a national database with atrial fibrillation (AF) undergoing mitral surgery. ${ }^{1}$ After rigorous propensity matching, the authors found 1784 pairs of patients (mitral surgery vs mitral surgery and ablation) to compare. We have to thank the authors for their careful statistical analysis of these 3568 cases. During the 12-year study period, 34,267 patients underwent mitral surgery, among them 11,381 patients who initially presented with AF. In other words, $33 \%$ of patients undergoing mitral surgery in European countries these days present with AF. The effects of AF on morbidity and mortality are well described. ${ }^{2}$ Can we afford to ignore such a frequent and surgically treatable disease? Unfortunately, this study found that only $21.5 \%$ of patients with AF undergoing mitral surgery had a concomitant surgical ablation. This is very low number. Badhwar and colleagues ${ }^{3}$ found that mitral operations had a rate of concomitant surgical ablation of $68.4 \%$ in the United States. The 2017 American Society of Thoracic Surgeons clinical practice guidelines assigned Class I, Level of evidence A for concomitant surgical ablation of AF at the time of mitral surgery, stating that surgical ablation for AF can be performed without additional risk of operative mortality or major morbidity. ${ }^{4}$

The limitation of the article by Suwalski and colleagues ${ }^{1}$ is that the authors do not have details of the surgical technique of AF ablation. This is extremely important. No doubt, this simple, standard, safe, and effective procedure can provide excellent results and this should encourage surgeons to perform AF ablation on many patients. Analyzing the literature and my own experience, I believe that cryoablation or a combination of cryoablation and bipolar radiofrequency ablation in the open left atrium-with a box lesion around the pulmonary veins and mitral isthmus line — can be the safe and effective procedure we need. ${ }^{5,6}$

A recent systematic review and meta-analysis of randomized controlled trials by McClure and colleagues ${ }^{7}$ found that surgical ablation of AF had no significant effect on

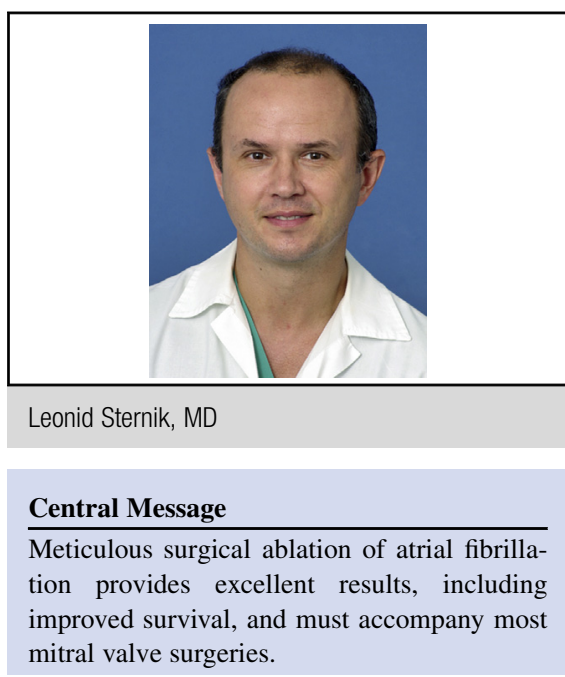

See Article page 1007.

mortality. In the present study, the survival benefit was shown on thousands of patients with long-term follow-up and strong statistical analysis. The survival benefit of surgical ablation was maintained in all patents, but the most benefit was appraised in low-risk patients such with European system for cardiac operative risk evaluation score 2 through 5 and younger than age 50 years. By analyzing the results of experienced surgical ablation centers we can find even better results. We have to keep in mind the authors' observation that the ablation benefit for high-risk patients is not so significant. Obviously, there are patients for whom ablation should be abandoned. These are very ill patients, patients with a long history of continued AF, patients with a huge left atrium, and re-do cases. But these patients make up the minority of mitral surgery cases.

Meticulous surgical ablation of AF must accompany most mitral valve surgeries. Let's run big databases in our institutions and countries.

\section{References}

1. Suwalski P, Kowalewski M, Jasiński M, Staromłyński J, Zembala M, Widenka K, et al. Survival after surgical ablation for atrial fibrillation in mitral valve surgery. Analysis from KROK (Polish nationwide heart surgery registry). J Thorac Cardiovasc Surg. 2019;157:1007-18.

2. Benjamin EJ, Wolf PA, D'Agostino RB. Impact of atrial fibrillation on the risk of death: the Framingham Heart Study. Circulation. 1998;98:946-52.

3. Badhwar V, Rankin JS, Ad N, Grau-Sepulveda M, Damiano RJ, Gillinov AM et al. Surgical ablation of atrial fibrillation in the United States: trends and propensity matched outcomes. Ann Thorac Surg. 2017;104:493-500. 
4. Badhwar V, Rankin JS, Damiano RJ Jr, Gillinov AM, Bakaeen FG, Edgerton JR, et al. The Society of Thoracic Surgeons 2017 clinical practice guidelines for the surgical treatment of atrial fibrillation. Ann Thorac Surg. 2017;103:329-41.

5. Sternik L, Kogan A, Luria D, Gilkson M, Malachy A, Levin S, et al. Box lesion in the open left atrium for surgical ablation of atrial fibrillation. J Thorac Cardiovasc Surg. 2014;147:956-9.
6. Gillinov M. Choice of surgical lesion set: answers from data. Ann Thorac Surg. 2007;84:1786-92.

7. McClure GR, Belley-Cote EP, Jaffer IH, Dvirnik N, An KR, Fortin G, et al Surgical ablation of atrial fibrillation: a systematic review and meta-analysis of randomized controlled trials. Europace. November 27, 2017 [Epub ahead of print]. 